\title{
Gas exchange, photosynthetic pigments, and growth in tomato: lettuce intercropping
}

Tatiana P.L. da Cunha-Chiamolera ${ }^{1 *}$, Arthur B. Cecilio Filho ${ }^{1}$, Durvalina M.M. dos Santos ${ }^{1}$, and Flávio J.R. Cruz ${ }^{1}$

\section{ABSTRACT}

The intercropping system is characterized by interspecific competition and leads to one of the most limiting abiotic factors for high plant yield in this cropping system. Plants under low light can carry significant weight in physiological parameters that can limit growth. Light is one of the abiotic factors that limits productivity; in the present study, it was hypothesized that tomato (Solanum lycopersicum L.) and lettuce (Lactuca sativa L.) intercropping in different transplanting periods promotes changes in gas exchange, photosynthetic pigments, and biomass accumulation in two lettuce cultivars. An experimental study was carried out in Jaboticabal, Sao Paulo, Brazil. The treatments consisted of a combination of the following factors: lettuce (one 'Lucy Brown' plant between two tomato plants and two 'Vanda' plants between tomato plants), two cultivation systems (intercropping and monoculture), and four lettuce transplanting periods $(0,7,14$. and $21 \mathrm{~d}$ after tomato transplanting). The experiment was a randomized block with a $3 \times 2 \times 4$ factorial design and four replicates. Transpiration and stomatal conductance were reduced in lettuce by insterspersing plants under a monoculture system. Lettuce-tomato intercropping severely reduced photosynthesis, fluorescence, chlorophyll pigment content, and DM accumulation. Therefore, 'Vanda' is better than 'Lucy Brown' for intercropping with tomato.

Key words: Lactuca sativa, photosynthesis, shading, Solanum lycopersicum, yield.

${ }^{1}$ Universidade Estadual Paulista (UNESP), Faculdade de Ciências Agrárias e Veterinárias, Campus de Jaboticabal, SP, 14884-900, Brasil. *Corresponding author (tatiana.pagan@hotmail.com).

Received: 10 April 2017.

Accepted: 5 October 2017.

doi:10.4067/S0718-58392017000400295

\section{INTRODUCTION}

Intercropping is a cultivation system that is used in many regions of the world to produce food or fiber, and it is aimed at greater crop productivity and high profitability. This system is a strategy to maximize land use when two or more species are simultaneously cultivated with cycles and/or different architectures and which do not need to be concurrently sown (Willey, 1979).

In vegetable species, intercropping conducted in greenhouses has been targeted to maximize the efficient use of this environment and be the most cost-effective with greater productivity in the same area. Intercropping is mainly used in the cultivation of vegetables due to fast growth and maturation, as well as high biomass productivity (Oliveira et al., 2010). However, the benefit of crop association requires that species not only have distinct but also complementary agronomic characteristics, which are key criteria in this type of cultivation system (Cecílio Filho et al., 2011; Chapagain and Riseman, 2014). In general, the main limiting factors for plant growth and development are related to the availability of water, nutrients, and light (Jose et al., 2006). In the case of intercropping, light intensity can be considered a limiting factor for plant growth because the canopy can shade the associated species (He et al., 2013; Gong et al., 2015). In low light, energy processes of plant metabolism will be reduced, such as ATP synthesis and carbohydrates, causing lower biomass production and decreased productivity (Su et al., 2014).

As an acclimatization mechanism, fluctuations in ambient light availability make plants exhibit slower leaf area growth to maximize light absorption due to the reduced quantity and quality of light (Dai et al., 2009; Pacheco et al., 2013; Saraiva et al., 2014). Even with increased shading due to the growth of larger species, leaf thickness is reduced and there is higher biomass allocation to roots, higher chlorophyll $a$ and $b$ contents for leaf area, and higher ratio between chlorophyll $b$ and $a$ of shaded plants (Boardman, 1977). Changes in the light environment influence leaf anatomy, physiology, and morphology (Hogewoning et al., 2010; Huang et al., 2011).

Therefore, competition for resources needed for plant growth and ecophysiological implications of space-time interaction between plants with contrasting architecture and cultivated under intercropping system should be considered for the production of smaller species (Ghanbari et al., 2010). Studies have found that shading caused by intercropping reduces plant physiological 
responses, thus reduced growth and productivity ( $\mathrm{Su}$ et al., 2014; Gong et al., 2015).

Lettuce (Lactuca sativa L.) and tomato (Solanum lycopersicum L.) are crops of great economic interest; they have different agronomic characteristics, which allow exploration of spatial and temporal complementarity of the available resources in an intercropping agroecosystem. The coexistence period between intercropped species, which depends on the transplanting period of the secondary crop as related to the main crop, significantly changes the complementarity between species, thus the agroeconomic viability of intercropping (Wu et al., 2012; Tringovska et al., 2015).

Based on the fact that light constitutes one of the limiting abiotic factors for productivity, the objective of this study was to evaluate the effect of the lettuce-tomato intercropping system at different transplanting periods with respect to gas exchange, chlorophyll pigments, and biomass accumulation.

\section{MATERIALS AND METHODS}

The experiment was conducted from 28 August 2013 to 15 February 2014 in a greenhouse at the Universidade Estadual Paulista (UNESP), Campus Jaboticabal (2115'22" S, 48 $15^{\prime} 58^{\prime}$ 'W; $575 \mathrm{~m}$ a.s.1.), Sao Paulo, Brazil. Two lettuce cultivars 'Lucy Brown' (crisphead group) and 'Vanda' (looseleaf group) as well as one tomato cultivar 'Débora Victory' of indeterminate growth and Santa Cruz fruit type were used. Mean tomato weight was $180 \mathrm{~g}$ and the cycle was approximately $115 \mathrm{~d}$. The experiment was a randomized block with a $3 \times 2 \times 4$ factorial design, including the following factors: lettuce (one 'Lucy Brown' plant between two tomato plants, and one/two 'Vanda' plants between tomato plants), two cropping systems (intercropping and monoculture), and four lettuce transplanting periods $(0$, 7, 14, and $21 \mathrm{~d}$ after tomato transplanting DATT]). Four replicates were performed. Each intercropping unit consisted of four tomato plants interspersed with lettuce plants. Plots with tomato and 'Lucy Brown' and 'Vanda' lettuce under monoculture had 4, 8, and 6 plants, respectively.

After sowing tomato and lettuce, trays were placed in a protected environment and watered daily until transferred to the cultivation trench $0.18 \mathrm{~m}$ wide at the base, $0.38 \mathrm{~m}$ wide, $0.20 \mathrm{~m}$ high, and $5.00 \mathrm{~m}$ long, and capacity of 280 L), which contained coconut fiber substrate, composed of $50 \%$ long fibers and $50 \%$ short fibers. The tomato plant was transplanted at the four-leaf stage after cotyledon leaf emergence with $1.10 \mathrm{~m} \times 0.40 \mathrm{~m}$ spacing (between rows $\times$ between plants). Plants were vertical with an individual stem and wrapped with plastic. 'Lucy Brown' and 'Vanda' lettuce seedlings were transplanted at the four-leaf stage after cotyledon leaf emergence. 'Lucy Brown' and 'Vanda' (one lettuce plant between tomato plants) were transplanted halfway between tomato plants ( $0.40 \mathrm{~m}$ from each other). Two 'Vanda' plants were transplanted between tomato plants at $0.20 \mathrm{~m}$ from each other (Figure 1).
Figure 1. Plant distribution in the experimental units: (A) lettuce monoculture, $(B)$ tomato monoculture, $(C)$ intercropping with one lettuce plant between tomato plants, and (D) intercropping with two lettuce plants between tomato plants.

(A)

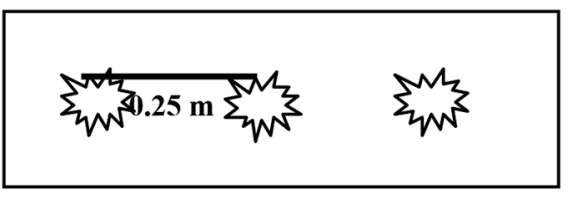

(B)

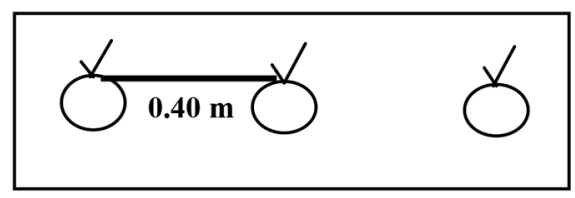

(C)

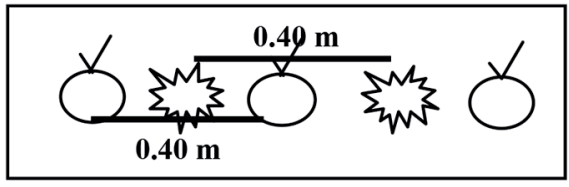

(D)

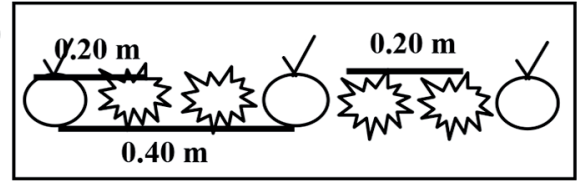

Drip irrigation was installed in each cultivation trench using self-emitters spaced at $0.40 \mathrm{~m}$. The automatic irrigation system was activated when the mean humidity value recorded by the sensors placed in the trenches reached $-4.0 \mathrm{kPa}$. Plants were grown in a complete nutrient solution for macronutrients and micronutrients (Muckle, 1993).

Photosynthetically active radiation (PAR) was collected above the tomato and lettuce canopies. Maximum and minimum temperature $\left({ }^{\circ} \mathrm{C}\right)$ observations, mean $\mathrm{RH}(\%)$, and solar radiation were measured every $15 \mathrm{~min}$ with a plant growth station (WatchDog 2475, Spectrum Technologies, Illinois, USA) located inside the greenhouse (Figure 2).

Physiological evaluations were performed on the first fully-expanded leaf of the lettuce plants $2 \mathrm{~d}$ before harvest. The following physiological evaluations were performed: (i) maximum quantum efficiency of photosystem II (PSII) $\left(\mathrm{F}_{\mathrm{v}} / \mathrm{F}_{\mathrm{m}}\right)$ by dark adaptation of a leaf blade segment for 30 min using an OS30p+ fluorometer (Opti-Sciences, Hudson, New Hampshire, USA) between 08:00 and 09:00 h, (ii) transpiration rate $(\mathrm{E})$, stomatal conductance $\left(\mathrm{g}_{\mathrm{s}}\right)$, and net photosynthetic rate $\left(\mathrm{P}_{\mathrm{N}}\right)$ using an infrared gas analyzer (IRGA) (LCpro+, ADC BioScientific, Hoddesdon, UK).

The source of light reading was $1200 \mathrm{~mol} \mathrm{~m}^{-2} \mathrm{~s}^{-1}$, while the $\mathrm{CO}_{2}$ concentration and $\mathrm{RH}$ in the chamber were $380 \pm 2 \mu^{-1} \mathrm{~mol}^{-1}$ and $70 \%$, respectively, according to He et al. (2013), (iii) photosynthetic pigment contents, chlorophyll $a(\mathrm{Chl} a)$, chlorophyll $b(\mathrm{Chl} b)$, and carotenoids (Car) were determined according to the methodology described by Lichtenthaler (1987), and (iv) growth was verified by obtaining shoot DM of lettuce harvested $28 \mathrm{~d}$ after transplanting. For this purpose, a randomly sampled plant was used, which was placed to dry in forced air 
Figure 2. Maximum and minimum temperature, mean relative humidity, and mean solar radiation incidence on tomato and lettuce (PAR $\mu \mathrm{mol} \mathrm{m} \mathrm{m}^{-2} \mathrm{~s}^{-1}$ ) every $5 \mathrm{~d}$ during lettuce crop growth.
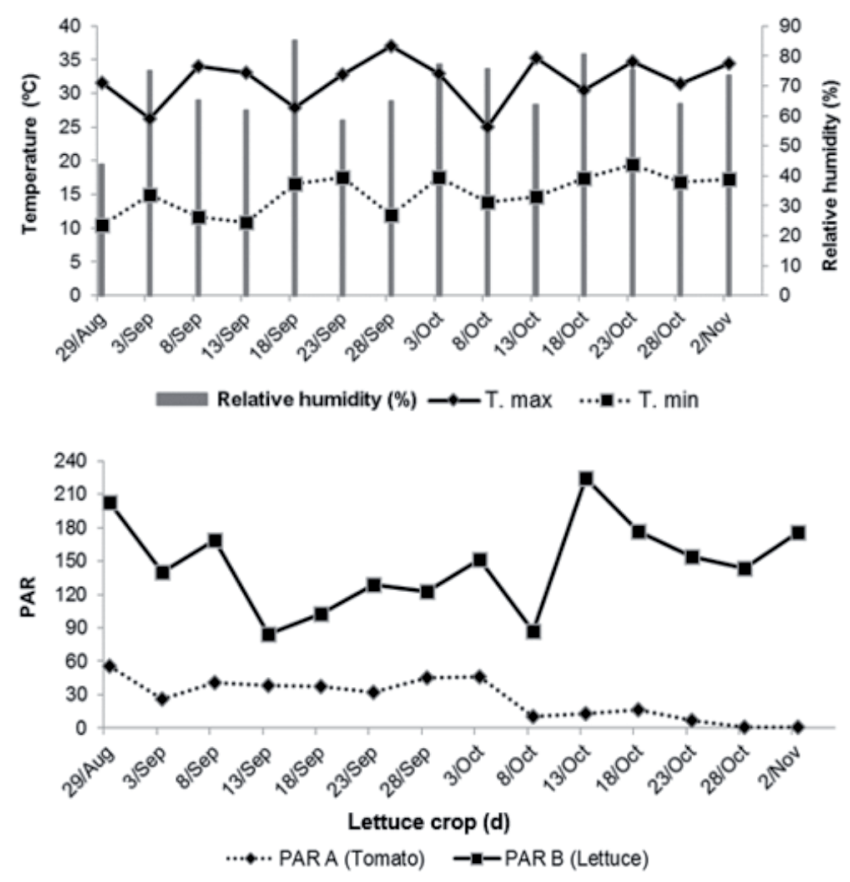

PAR: Photosynthetically active radiation.

circulation at $65^{\circ} \mathrm{C}$ for $96 \mathrm{~h}$. After drying, samples were weighed and dry weight determined with an analytical precision balance. Data were subjected to ANOVA by the F-test and treatment means were compared by Tukey's test at $5 \%$ probability.

\section{RESULTS}

'Lucy Brown' lettuce had lower transpiration (E) and stomatal conductance $\left(\mathrm{g}_{\mathrm{s}}\right)$ than 'Vanda' under the intercropping system (31.5\% and $53.9 \%$, respectively) and under monoculture ( $42.2 \%$ and $68.5 \%$, respectively) (Figures 3A, 3B). For 'Vanda', regardless of whether one or two plants were evaluated, $\mathrm{E}$ values were the same (Figure $3 \mathrm{~A})$. Observed results for $\mathrm{g}_{\mathrm{s}}$ corroborate results from the interaction between lettuce and cultivation systems for E; therefore, higher $\mathrm{g}_{\mathrm{s}}$ leads to a higher $\mathrm{E}$ rate (Figures $3 \mathrm{~A}$, $3 B)$. For both lettuce cultivars, $g_{s}$ values from intercropping were lower, over $40 \%$, as compared to monoculture (Figure $3 \mathrm{~B})$. This result is also related to the photosynthesis $\left(\mathrm{P}_{\mathrm{N}}\right)$ response, which was $55.2 \%$ lower in the intercropping system than in monoculture (Figure 3C). Transplanting periods also influenced the evaluated parameters. Such time periods in the intercropping system influenced $\mathrm{g}_{\mathrm{s}}$ in intercropped plants (Figure 3D). Lettuce in the intercropping system $14 \mathrm{~d}$ after transplanting showed reduced $\mathrm{g}_{\mathrm{s}}$, E, and $\mathrm{P}_{\mathrm{N}}$ with values of $74.0 \%, 20.5 \%$, and $18.3 \%$, respectively, compared to transplanting on the same day, that is, 0 DATT (Figures 3D, 3E, 3F).
Results for $\mathrm{E}, \mathrm{g}_{\mathrm{s}}$, and $\mathrm{P}_{\mathrm{N}}$ showed that gas exchange of 'Lucy Brown' plants was lower than in 'Vanda' plants (one or two plants) at 0 and 21 DATT (Figure 4). Taking into account transplanting periods, $\mathrm{E}$ values were variable for each cultivar (Figure 4A). Compared to the first day of transplanting at 7 and $14 \mathrm{~d}$, the results of $\mathrm{E}$ and $\mathrm{g}_{\mathrm{s}}$ decreased for 'Vanda', regardless of the number of plants (Figure 4A, 4B). In 'Vanda' lettuce, regardless of the number of lettuce plants between tomato plants, $\mathrm{E}, \mathrm{g}_{\mathrm{s}}$, and $\mathrm{P}_{\mathrm{N}}$ were significantly similar (Figure 4).

Although $\mathrm{F}_{\mathrm{v}} / \mathrm{F}_{\mathrm{m}}$ values were significant for the lettuce cultivar and cultivation system, the transplanting period did not change $\mathrm{F}_{\mathrm{v}} / \mathrm{F}_{\mathrm{m}}$. For 'Lucy Brown', $\mathrm{F}_{\mathrm{v}} / \mathrm{F}_{\mathrm{m}}$ was $1.4 \%$ lower than 'Vanda' with either one or two plants between tomato plants (Figure 5A). Plants in the intercropping system exhibited a 0.02 reduction of $F_{v} / F_{m}$ compared to monoculture (Figure 4B). Light reduction in the canopy of lettuce plants reduced $\mathrm{F}_{\mathrm{v}} / \mathrm{F}_{\mathrm{m}}$ and therefore $\mathrm{P}_{\mathrm{N}}$ and $\mathrm{Chl}$ (Figures 3C, 5B, 6C).

The quantification of photosynthetic pigments in lettuce cultivars showed that chloroplast pigment contents were always higher in 'Lucy Brown' than 'Vanda', regardless of the cropping system and transplanting periods of the lettuce plants (Figures 6A, 6B, 6E, 6F, 7A, 7C). In the intercropping system, because lettuce was transplanted later, the values of photosynthetic pigments were higher (Figure 6C, 6D). Regardless of the cropping system, lettuce plants had a higher Car ratio when transplanted later (Figure 7B).

The lower growth of 'Lucy Brown' when compared to 'Vanda' (Figures 8A, 8C) is corroborated by the results found for $\mathrm{E}, \mathrm{g}_{\mathrm{s}}$, and $\mathrm{P}_{\mathrm{N}}$ (Figure 4). Although the monoculture system resulted in lower growth at 21 DATT, the intercropping system was more harmful to lettuce plant growth, thus showing a higher decrease in lettuce dry matter in all transplanting periods (Figure 8B).

\section{DISCUSSION}

Under the lettuce-tomato intercropping system, lower light intensity intercepted by lettuce plants can be the limiting factor because more than half of the radiation is lost due to shading caused by the tomato plants (Figure 2 ). It is well known that low irradiance on plants has a direct effect on physiological characteristics (Zhang et al., 2008; Ghanbari et al., 2010). Photosynthesis is extremely dependent on light, so that shade-tolerant plants (shade plants) have peculiar photosynthetic characteristics to adapt to environments with different light intensities. According to Dai et al. (2009) and Huang et al. (2011), plants can modify the photosynthetic apparatus (e.g., provision of chloroplasts focuses on light interception by pigments or greater synthesis of chlorophyll) to adapt to the light deficit of the environment in which they are living.

In the present study, tomato shading on lettuce (intercropped) caused significant reduction in $\mathrm{E}, \mathrm{g}_{\mathrm{s}}$, and $\mathrm{P}_{\mathrm{N}}$ (Figures 2 and 3), indicating that increased stomatal resistance, due to lower $\mathrm{g}_{\mathrm{s}}$, leads to reduced $\mathrm{P}_{\mathrm{N}}$ because 
Figure 3. Leaf transpiration (E) (A and E), stomatal conductance ( $\left.g_{S}\right)$ (B and D), and net photosynthesis $\left(P_{N}\right)(C$ and $F)$ of lettuce ('Lucy Brown', 'Vanda' 1 and 2 plants) under two cropping systems (monocropping and intercropping) and four lettuce transplanting periods $(0,7,14$, and $21 \mathrm{~d}$ after tomato transplanting).
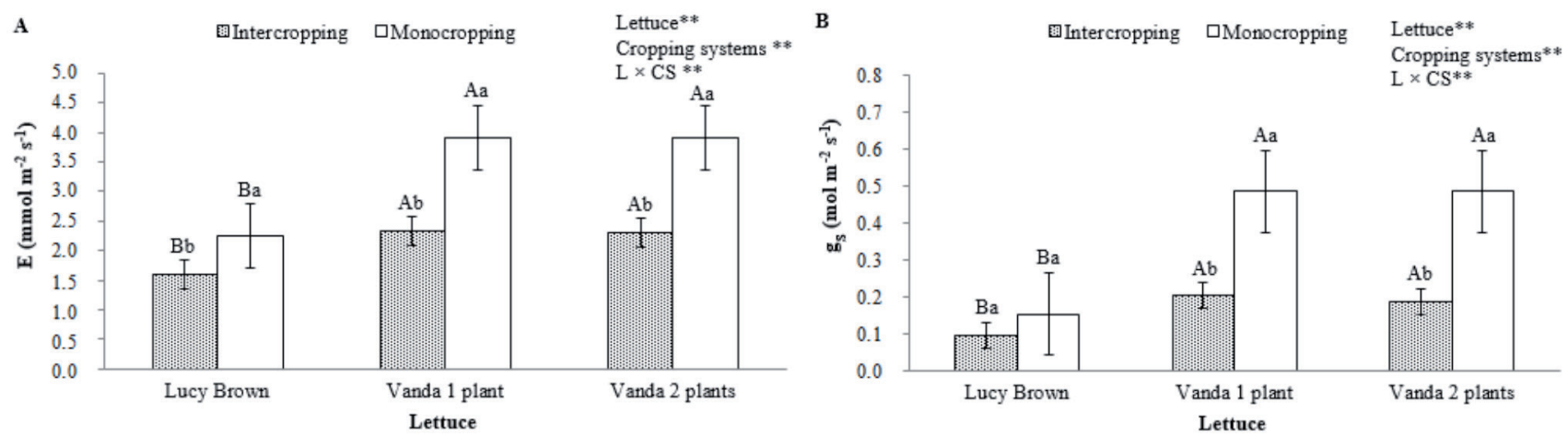

C

D
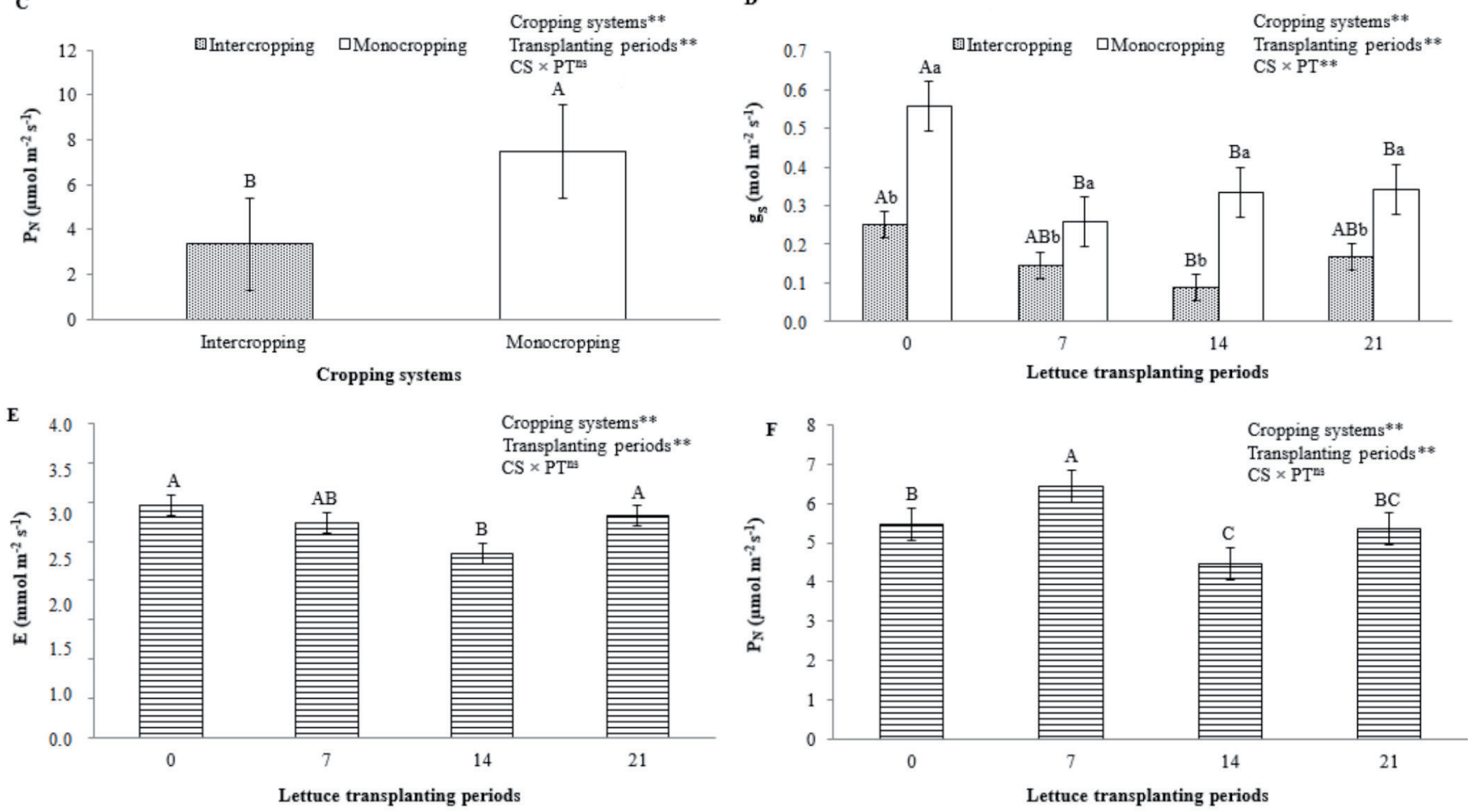

Bars indicate standard deviation of the mean of four replicates.

${ }^{\mathrm{ns}}$ Nonsignificant; $* \mathrm{p} \leq 0.05 ; * * \mathrm{p} \leq 0.01$.

The same uppercase letters between transplanting periods and lettuce cultivars do not differ from each other according to Tukey's test at 5\% probability. The same lowercase letters within lettuce cultivars and transplanting periods do not differ from each other according to Tukey's test at 5\% probability.

of less $\mathrm{C}$ assimilation in determining the photosynthetic process. Our results corroborate those mentioned by Mendes et al. (2013) and Gong et al. (2015), who found that low brightness significantly reduces gas exchanges $\left(\mathrm{E}, \mathrm{g}_{\mathrm{s}}\right.$, and $\mathrm{P}_{\mathrm{N}}$ ) in shaded plants cultivated under intercropping. Less cooling in the lettuce leaves may have occurred, caused by minimizing $\mathrm{E}$ from the reduction of $\mathrm{g}_{\mathrm{s}}$. Indirectly, the lowest incident brightness may have triggered other physiological changes in lettuce plants, which were not addressed in our study but which could be considered in future research work.

Regarding transplanting periods, when transplanting was later, lower light availability for plants led to lower growth and biomass accumulation (Figures 3E, 3F, 4, 8B). This is related to higher shading on plants, which prevents light interception required for stomatal opening. In the early morning hours, the incidence of blue light from the light spectrum is not absorbed by the leaves because the light has a characteristically shorter wavelength and more energy; it is decisive in the opening movement of the stomata that does not occur at the maximum opening of stomatal pore, and therefore results in lower $\mathrm{g}_{\mathrm{s}}$ and $\mathrm{P}_{\mathrm{N}}$. According to $\mathrm{Su}$ et al. (2014), this condition is known as stomatal limitation of photosynthesis. These results are consistent with those found by other researchers, who evaluated the effect of shading on the growth of various crops under intercropping 
Figure 4. Leaf transpiration (E) (A), stomatal conductance $\left(\mathrm{g}_{\mathrm{S}}\right)$ $(B)$, and net photosynthesis $\left(P_{\mathrm{N}}\right)(\mathrm{C})$ of lettuce ('Lucy Brown' and 'Vanda' 1 and 2 plants) at four lettuce transplanting periods $(0,7,14$, and $21 \mathrm{~d}$ after tomato transplanting).
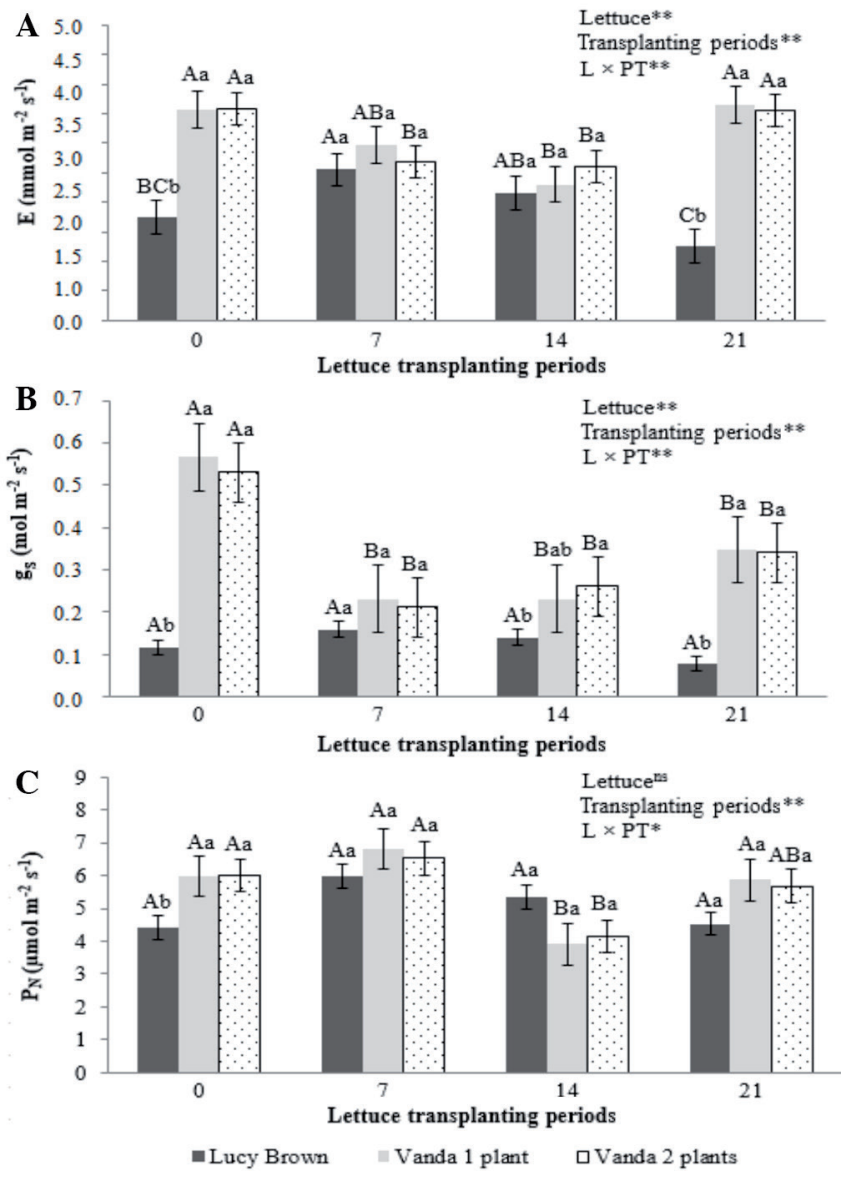

Bars indicate the standard deviation of the mean of four replicates.

${ }^{\mathrm{ns}}$ Nonsignificant; $* \mathrm{p} \leq 0.05 ; * \mathrm{*} \leq 0.01$.

The same uppercase letters between transplanting periods do not differ from each other according to Tukey's test at $5 \%$ probability. The same lowercase letters within transplanting periods, do not differ from each other according to Tukey's test at $5 \%$ probability.

at different transplanting periods (Rezende et al., 2011; Cecílio Filho et al., 2011; 2013; Su et al., 2014).

The estimated maximum quantum efficiency of photochemical activity of PSII is verified by determining the fluorescence of $\mathrm{Chl} a$. This physiological parameter has been frequently used to detect changes in the photosynthetic system due to biotic and abiotic stresses because reduced fluorescence indicates inhibited photochemical activity (Dai et al., 2009; He et al., 2013). In fact, there was less $\mathrm{P}_{\mathrm{N}}$ and $\mathrm{F}_{\mathrm{v}} / \mathrm{F}_{\mathrm{m}}$ in the intercropping system compared to monoculture (Figures 3C and 5B). The results of our study corroborate those observed by Su et al. (2014) and Gong et al. (2015).

Chlorophyll concentration can be used as an indicator of stress in plants because it is present in leaf chloroplasts to participate in light reactions that are very important for the photosynthetic process to take place. The highest chlorophyll and carotenoid contents under shading conditions in lettuce plants can be related to the compensatory effect of species
Figure 5. Maximum quantum yield of photosystem II $\left(\mathbf{F}_{v} / \mathbf{F}_{m}\right)$ of lettuce ('Lucy Brown' and 'Vanda' 1 and 2 plants) under two cropping systems (monocropping and intercropping).
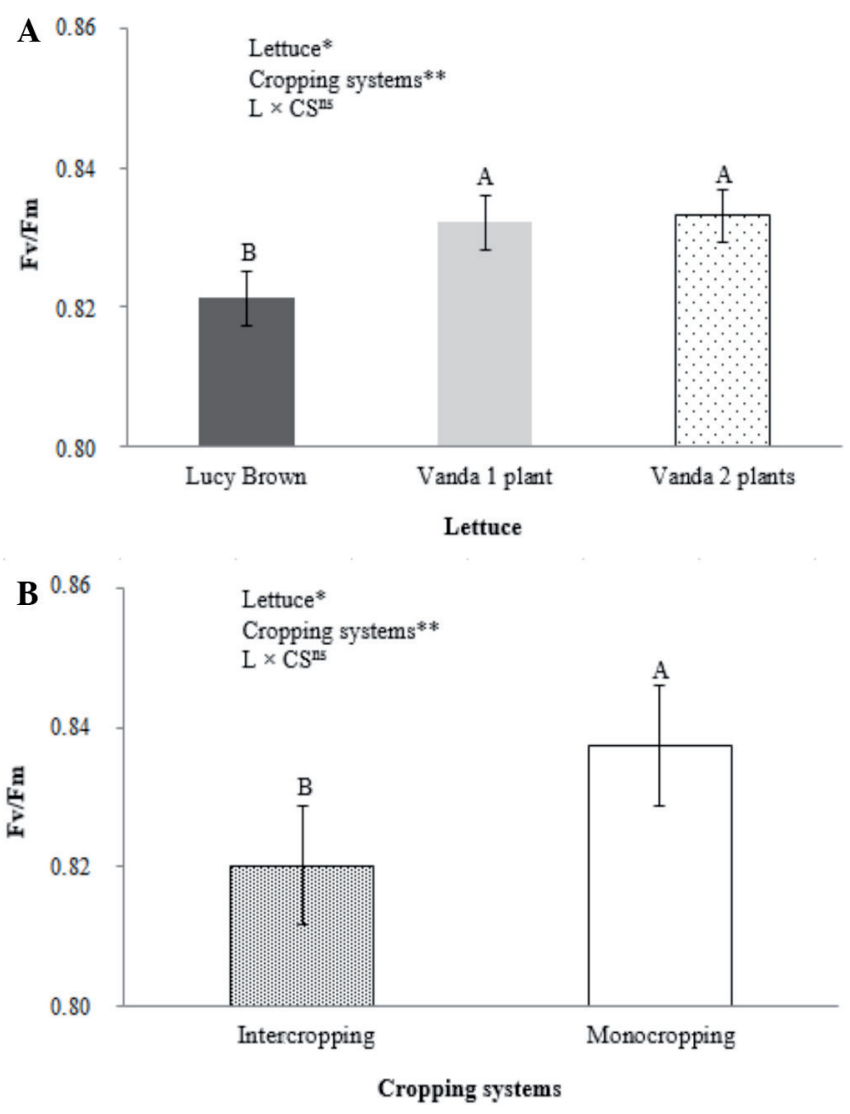

Bars indicate the standard deviation of the mean of four replicates.

${ }^{n s}$ Nonsignificant; * $\mathrm{p} \leq 0.05 ; * * \mathrm{p} \leq 0.01$.

The same uppercase letters between lettuce cultivars and cropping system do not differ statistically according to Tukey's test ( $\mathrm{p} \leq 0.05$ ).

to a lower amount of available radiation (Figures 6 and 7). In leaves under low light, a higher $\mathrm{Chl} b$ content is an important feature because this type of chlorophyll captures light energy at different wavelengths and transfers it to the oxidizable Chl $a$ (P680 and P700), which is a fundamental reaction center of the photochemical stage to produce ATP and NADPH. Observations by Scalon et al. (2002) revealed that increased $\mathrm{Chl} b$ is an adaptation mechanism to lower the light intensity condition.

However, based on the hypothesis that chlorophyll can be used to estimate photosynthetic efficiency, the results of the present study showed that the highest chlorophyll contents during the transplanting period was found in 'Lucy Brown', and it was not decisive for growth because it showed lower biomass accumulation (Figures 6E, 6F, 8C). On the other hand, 'Vanda' exhibited lower chlorophyll contents and higher growth (DM accumulation); this shows that it is more efficient in chlorophyll content and growth ratio than 'Lucy Brown' (Figures 6E, 6F, and 8C). The results of our study for Chl $b$ concur with those found by Su et al. (2014) and Gong et al. (2015), who confirmed that shading causes increased $\mathrm{Chl} b$ content in leaves and decreased plant 
Figure 6. Chlorophyll $a$ (A, C, and E) and chlorophyll $b$ (B, D, and F) of lettuce ('Lucy Brown' and 'Vanda' 1 and 2 plants) under two cropping systems (monocropping and intercropping) in four lettuce transplanting periods (0, 7, 14, and $21 \mathrm{~d}$ after tomato transplanting).
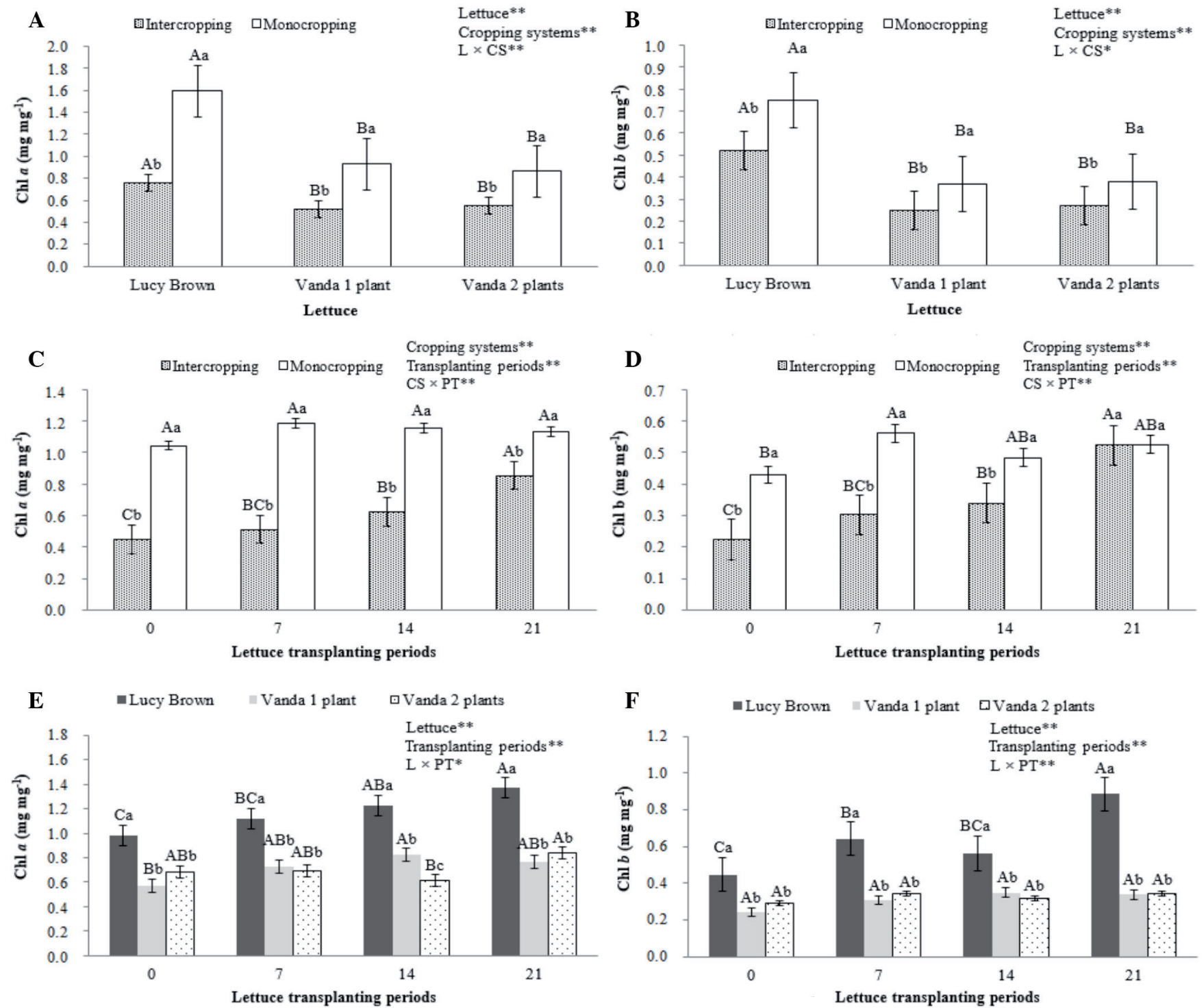

Bars indicate the standard deviation of the mean of four replicates.

${ }^{\mathrm{ns}}$ Nonsignificant; $* \mathrm{p} \leq 0.05 ; * * \mathrm{p} \leq 0.01$.

The same uppercase letters between transplanting periods and lettuce cultivars do not differ from each other according to Tukey's test at $5 \%$ probability. The same lowercase letters within lettuce cultivars and transplanting periods do not differ from each other according to Tukey's test at $5 \%$ probability.

biomass accumulation. Shading can also reduce biomass production and the accumulation of biomass from the secondary crop (in this case, lettuce plants) in intercropping systems (Reynolds et al., 2007; Peng et al., 2009). This is associated with the lowest available brightness and reduced photosynthetic rate due to light interception caused by tomato plants (Ghanbari et al., 2010). Results for $\mathrm{P}_{\mathrm{N}}$, E, $\mathrm{g}_{\mathrm{s}}$, and photosynthetic pigments in lettuce plants subjected to shading by intercropping had lower values for these physiological parameters, which directly caused biomass reduction (Figure 8). This finding, on average led to a $74.9 \%$ reduction in lettuce productivity (Figure $8 \mathrm{~B}$ ). Such a significant decrease in productivity was caused by shading of tomato plants. Lettuce plants in monoculture were not restricted in the amount of luminosity and achieved higher productivity. This also occurred in the research of several authors who evaluated lettuce-tomato intercropping (Yan et al., 2010; Cecílio Filho et al., 2011; Su et al., 2014; Tringovska et al., 2015), and corroborates our results.

\section{CONCLUSIONS}

Shading conditions imposed by tomato-lettuce intercropping reduced gas exchange, chlorophyll pigment contents, and secondary crop (lettuce) growth rate. When lettuce was transplanted later in relation to tomato, shading of tomato on lettuce plants was higher and caused harmful effects on physiological parameters and DM accumulation. In 
Figure 7. Carotenoids (Car) of lettuce 'Lucy Brown' and 'Vanda' 1 and 2 plants under two cropping systems (monocropping and intercropping) in four lettuce transplanting periods $(0,7,14$, and $21 \mathrm{~d}$ after tomato transplanting).
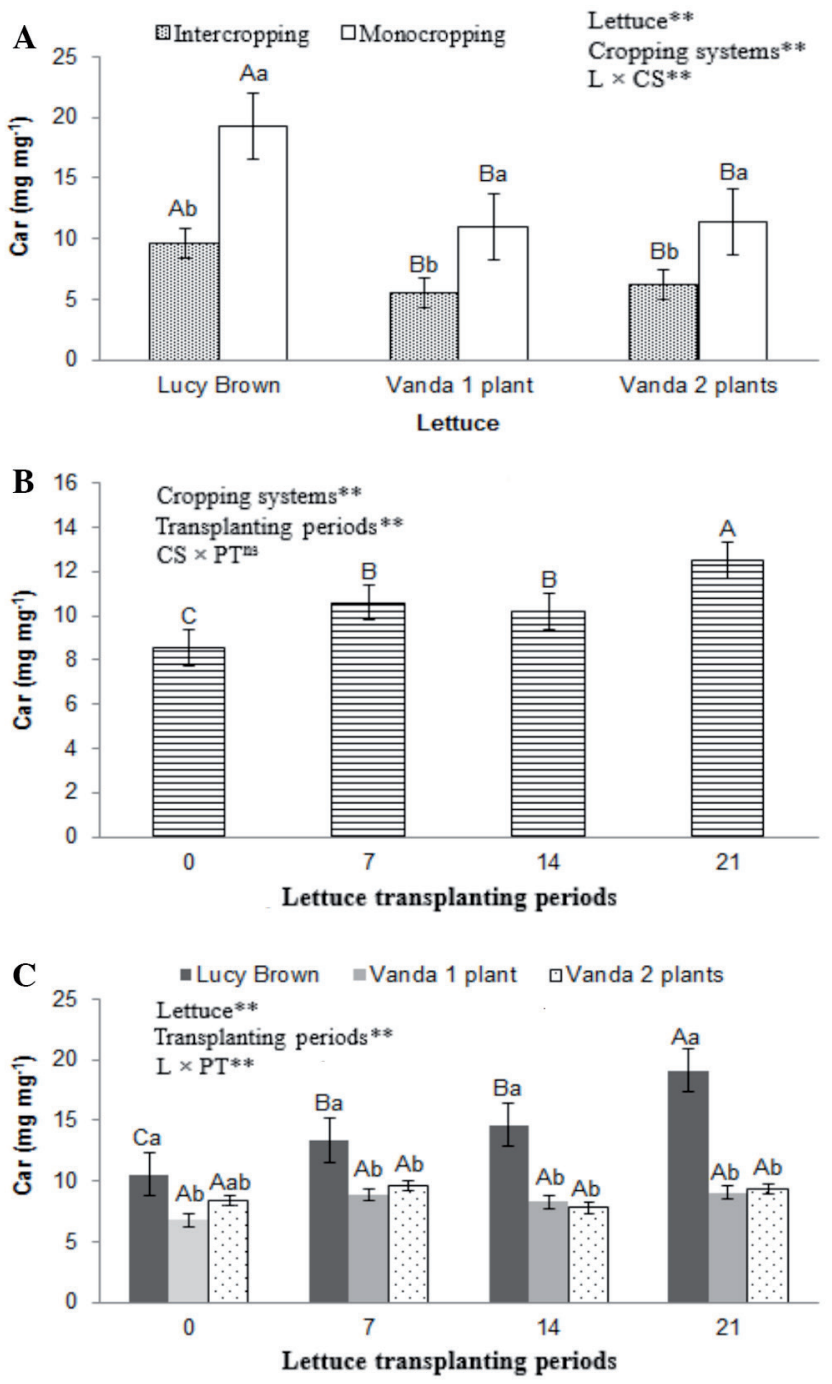

Bars indicate the standard deviation of the mean of four replicates. F-test: ${ }^{\mathrm{ns}}$ Nonsignificant; $* \mathrm{p} \leq 0.05 ; * * \mathrm{p} \leq 0.01$.

The same uppercase letters between transplanting periods and lettuce cultivars do not differ from each other according to Tukey's test at 5\% probability. The same lowercase letters within lettuce cultivars and transplanting periods do not differ from each other according to Tukey's test at $5 \%$ probability.

the intercropping system with tomato, 'Vanda' was more productive than 'Lucy Brown' plants. However, to obtain higher productivity, transplanting 'Vanda' lettuce should be carried out on the same day as tomato transplanting.

\section{ACKNOWLEDGEMENTS}

The second author thanks Conselho Nacional de Desenvolvimento Científico e Tecnológico (CNPq) for the resources to fund the research.
Figure 8. Growth (g DM plant ${ }^{-1}$ ) of lettuce ('Lucy Brown' and 'Vanda' 1 and 2 plants) under two cropping systems (monocropping and intercropping) in four lettuce transplanting periods $(0,7,14$, and $21 \mathrm{~d}$ after tomato transplanting).
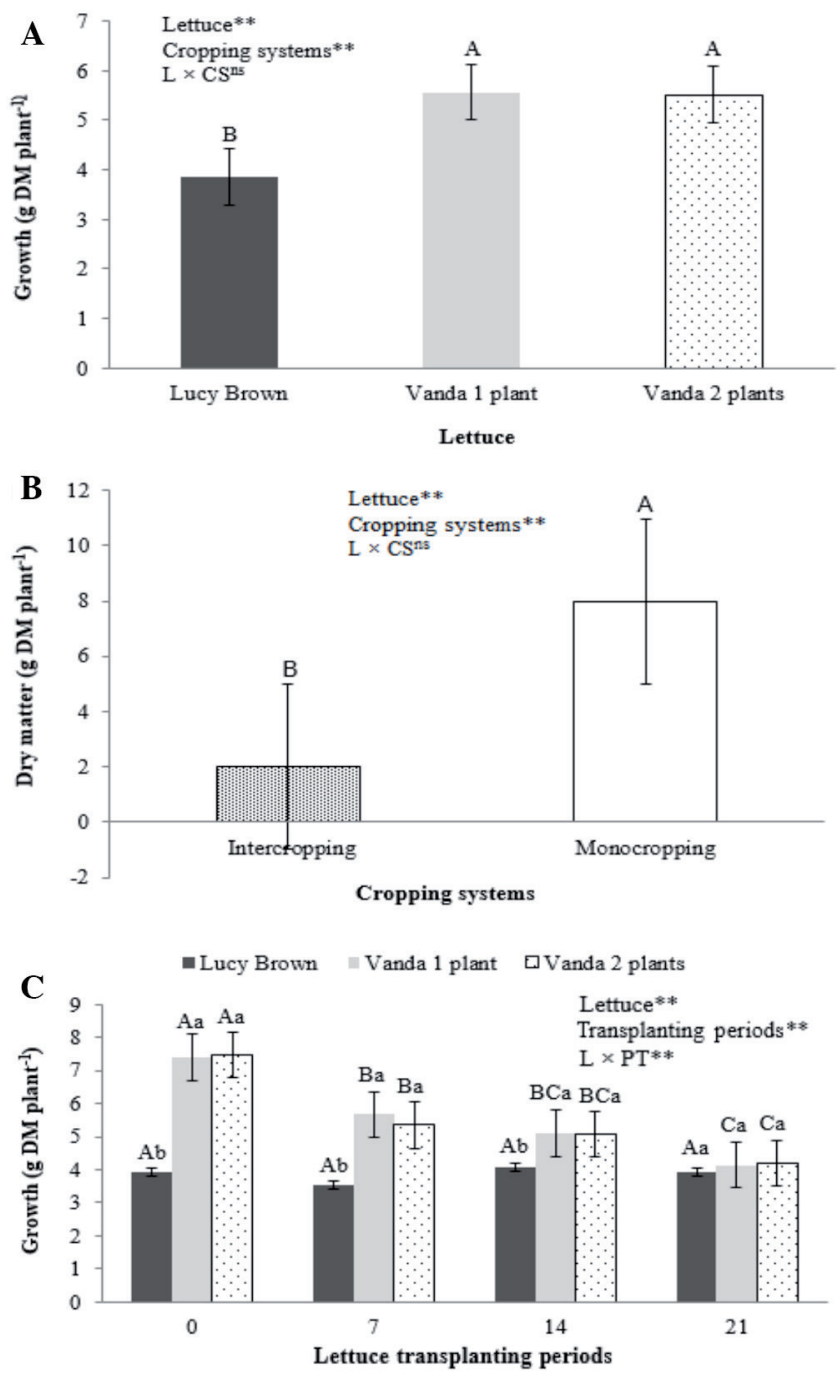

Bars indicate the standard deviation of the mean of four replications. F-test: ${ }^{\mathrm{ns}}$ Nonsignificant; *p $\leq 0.05 ; * * \mathrm{p} \leq 0.01$.

The same uppercase letters between transplanting periods and lettuce cultivars do not differ from each other according to Tukey's test at 5\% probability. The same lowercase letters within lettuce cultivars and transplanting periods do not differ from each other according to Tukey's test at $5 \%$ probability.

\section{REFERENCES}

Boardman, N.K. 1977. Comparative photosynthesis of sun and shade plants. Annual Review of Plant Physiology 28:355-377.

Cecílio Filho, A.B., Bezerra Neto, F., Rezende, B.L.A., Grangeiro, L.C., and Lima, J.S.S. 2013. Indices of competition and bioagroeconomic efficiency of lettuce and tomato intercrops in greenhouse. Australian Journal of Crop Science 7:809-819.

Cecílio Filho, A.B., Rezende, B.L.A., Barbosa, J.C., and Grangeiro, L.C. 2011. Agronomic efficiency of intercropping tomato and lettuce. Anais da Academia Brasileira de Ciências 83:1109-1119. 
Chapagain, T., and Riseman, A. 2014. Barley-pea intercropping: Effects on land productivity, carbon and nitrogen transformations. Field Crop Research 166:18-25.

Dai, Y.J., Shen, Z.G., Liu, Y., Wang, L., Hannaway, D., and Lu, H. 2009. Effects of shade treatments on the photosynthetic capacity, chlorophyll fluorescence, and chlorophyll content of Tetrastigma hemsleyanum Diels et Gilg. Environmental and Experimental Botany 65:177-182.

Ghanbari, A., Dahmardeh, M., Siahsar, B.A., and Ramroudi, M. 2010. Effect of maize (Zea mays L.) - cowpea (Vigna unguiculata L.) intercropping on light distribution, soil temperature and soil moisture in arid environment. Journal Food, Agriculture and Environment 8:102-108.

Gong, W.Z., Jiang, C.D., Wu, Y.S., Chen, H.H., Liu, W.Y., and Yang, W.Y. 2015. Tolerance vs. avoidance: two strategies of soybean (Glycine max) seedlings in response to shade in intercropping. Photosynthetica 53:259-268.

He, J., Quin, L., and Lee, S.K. 2013. Root-zone $\mathrm{CO}_{2}$ and root-zone temperature effects on photosynthesis and nitrogen metabolism of aeroponically grown lettuce (Lactuca sativa L.) in the tropics. Photosynthetica 51:330-340.

Hogewoning, S.W., Trouwborst, G., Maljaars, H., Poorter, H., Ieperen, W.V., and Harbinson, J. 2010. Blue light dose-responses of leaf photosynthesis, morphology, and chemical composition of Cucumis sativus grown under different combinations of red and blue light. Journal of Experimental Botany 61:3107-3117.

Huang, D., Wu, L., Chen, J.R., and Dong, L. 2011. Morphological plasticity, photosynthesis and chlorophyll fluorescence of Athyrium pachyphlebium at different shade levels. Photosynthetica 49:611-618.

Jose, S., Williams, R., and Zamora, D. 2006. Belowground ecological interactions in mixed-species forest plantations. Forest Ecology and Management 233:231-239.

Lichtenthaler, H.K. 1987. Chlorophylls and carotenoids: pigments of photosynthetic biomembranes. Methods in Enzymology 148:350-382.

Mendes, M.M.S., Lacerda, C.F., Cavalcante, A.C.R., Fernandes, F.E.P., e Oliveira, T.S. 2013. Desenvolvimento do milho sob influência de árvores de pau-branco em sistema agrossilvipastoril. Pesquisa Agropecuária Brasileira 48:1342-1350.

Muckle, M.E. 1993. Hydroponic nutrients. $3^{\text {rd }}$ ed. Growers Press, Princeton, British Columbia, Canada.

Oliveira, E.Q., Souza, R.J., Cruz, M.C.M., Marques, V.B., e França, A.C. 2010. Produtividade de alface e rúcula, em sistema consorciado, sob adubação orgânica e mineral. Horticultura Brasileira 28:36-40.
Pacheco, F.V., Silveira, H.R.O., Alvarenga, A.A., Alvarenga, I.C.A., Pinto, J.E.B.P., and Lira, J.M.S. 2013. Gas exchange and production of photosynthetic pigments of Piper aduncum L. grown at different irradiances. American Journal of Plant Sciences 4:114-121.

Peng, X., Zhang, Y., Cai, J., Jiang, Z., and Zhang, S. 2009. Photosynthesis, growth and yield of soybean and maize in a tree-based agroforestry intercropping system on the Loess Plateau. Agroforestry Systems 76:569-577.

Reynolds, P.E., Simpson, J.A., Thevathasan, N.V., and Gordon, A.M. 2007. Effects of tree competition on corn and soybean photosynthesis, growth, and yield in a temperate tree-based agroforestry intercropping system in southern Ontario, Canada. Ecological Engineering 29:362-371.

Rezende, B.L.A., Cecílio Filho, A.B., Barros Junior, A.P., Porto, D.R.Q., and Martins, M.I.E.G. 2011. Economic analysis of cucumber and lettuce intercropping under greenhouse in the winter-spring. Anais da Academia Brasileira de Ciências 83:705-717.

Saraiva, G.F.R., Souza, G.M., e Rodrigues, J.D. 2014. Aclimatação e fisiologia de mudas de guanandi cultivadas em telas de sombreamento foto-protetoras. Colloquium Agrariae 10:1-10.

Scalon, S.P.Q., Mussury, R.M., Rigoni, M.R., e Veraldo, F. 2002. Crescimento inicial de mudas de espécies florestais nativas sob diferentes níveis de sombreamento. Revista Árvore 26:1-5.

Su, B.Y., Song, Y.X., Song, C., Cui, L., Yong, T.W., and Yang, W.Y. 2014. Growth and photosynthetic responses of soybean seedlings to maize shading in relay intercropping system in Southwest China. Photosynthetica 52:332-340.

Tringovska, I., Yankova, V., Markova, D., and Mihov, M. 2015. Effect of companion plants on tomato greenhouse production. Scientia Horticulturae 186:31-37.

Willey, R.W. 1979. Intercropping - its importance and research needs. Part 1 - Competition and yield advantage. Field Crops Abstracts 32:1-10.

Wu, K., Fullen, M.A., An, T., Fan, Z., Zhou, F., Xue, G., et al. 2012. Above- and below-ground interspecific interaction in intercropped maize and potato: A field study using the 'target' technique. Field Crop Research 139:63-70.

Yan, Y., Gong, W., Yang, W., Wan, Y., Chen, X., Chen, Z., et al. 2010. Seed treatment with uniconazole powder improves soybean seedling growth under shading by corn in relay strip intercropping system. Plant Production Science 13:367-374.

Zhang, L., Van Der Werf, W., Bastiaans, L., Zhang, S., Li, B., and Spiertz, J.H.J. 2008. Light interception and utilization in relay intercrops of wheat and cotton. Field Crop Research 107:29-42. 